\title{
Letter to the editor concerning "Most cited 100 articles from Turkey on abdominal wall hernias: a bibliometric study"
}

Arda Işık $\left.\right|^{1}(\mathbb{D})$, Deniz Fırat ${ }^{2}(\mathbb{D})$

${ }^{1}$ Department of General Surgery, Istanbul Medeniyet University School of Medicine, Istanbul, Turkey

${ }^{2}$ Clinic of General Surgery, Bursa Training and Research Hospital, Bursa, Turkey

Cite this article as: Işık A, Firat D. Letter to the editor concerning "Most cited 100 articles from Turkey on abdominal wall hernias: a bibliometric study". Turk J Surg 2021; 37 (2): 193-194.

\section{Corresponding Author}

Arda Işık

E-mail: kararda@yahoo.com

Received: 23.07.2020

Accepted: 07.04 .2021

Available Online Date: 30.06 .2021

OCopyright 2021 by Turkish Surgical Society Available online at www.turkjsurg.com

DOI: $10.47717 /$ turkjsurg.2021.4973
Dear Editor,

We read the article "Most cited 100 articles from Turkey on abdominal wall hernias: a bibliometric study" by Kulacoğlu et al (1). It is a very interesting, valuable and encouraging study for abdominal wall hernias especially for inguinal hernias. However, we think a highly cited article from Turkey written by Isik et al. "Metalloproteinases and Their Inhibitors in Patients with Inguinal Hernia" (Figure 1) published at World Journal of Surgery in 2017 should be ranked (2). We attached the images of citations of Web of Science/Google Scholar (Figure 2-3) for their research in our country $(3,4)$.

> World J Surg. 2017 May;41(5):1259-1266. doi: 10.1007/s00268-016-3858-6.

Metalloproteinases and Their Inhibitors in Patients with Inguinal Hernia

Arda Isik ${ }^{1}$, Cebrail Gursul ${ }^{2}$, Kemal Peker ${ }^{3}$, Merve Aydın ${ }^{4}$, Deniz Firat ${ }^{3}$, Ismayil Yılmaz ${ }^{3}$

Affiliations + expand

PMID: 28050662 DOI: 10.1007/s00268-016-3858-6

Web of Science

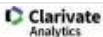
seart:

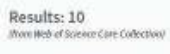

You searched for: TOPC: inguind

horvia) .... Mor

Createanalert

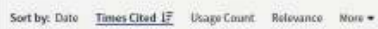

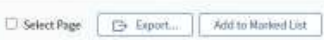

Metalloproteinases and Their Inhibitron in Patents with Inguinal Hermia

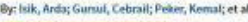

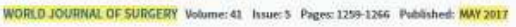

int Analyze Results LuA Creste Citation Aleport

Timercited: 19

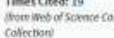
Colferone

Figure 1. Published article at World Journal of Surgery in 2017 by Isik et al. 


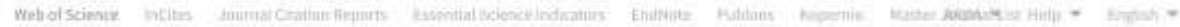

\section{Web of Science}

\section{Clarivate
Analytics}

Search Search Resuits

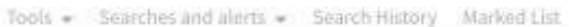

\section{Citing Articles: 15 from thab of scioncre cone Callocioni \\ For Metalloproteinases and Their Inhibitors in Patients with Inguinal Hernia ...tess \\ Times Cited Counts \\ 19 in Al Dosatioses \\ ig h Web of soience Core Codiection \\ Q in Mrabic Citation inse: \\ Jin Bosis Chation inder \\ oin Chinese science Citanion oxtatose \\ o data sees in Data Citerion inder \\ Qpublication in Data Clatorion hose \\ oin fussian Sounce cation india \\ a in Sclelo Claribn nder \\ View Additional Times Cited Counts}

Refine Results

Search within results for... $Q$

Filter results by:

D Open recoss |144]

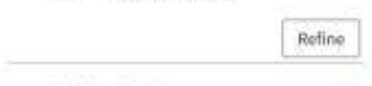

Publication Years

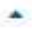

$\square 2011 ; 4\}$

2017 (11)
Sort by: Date If Times Cited Usage Count Hore

$\square$ Select Page $\mathrm{G}$ Export... Add to Marbed List

1. Postoperative treatment following open incisional hemia repair: $A$ survey and a review of literature

By: Paasch, Christoph; Anders, Stefan; Strik, Martin w. INTERNATIONAL JOURNAL OF SURGERY Volume: 53 Pages: 320-325 Published: MAY 2018

(6) Free Full Text from publisher View Abstract *

2. Fibrin glue mesh fixation combined with mesenchymat stem cells or exosomes modulates the inflammatory reaction in a murine model of incisional hernia By: Blazquez, Rebeca; Miguet Sanchez-Margallo, Francisco; Alvarez, Veronica; et aL.

ACTA BIOMATERIALIA Volume: 71 Pages: 318-329 Published: APR 152018

(4) Vlew Abstract -

3. Evaluation of Multislice Spiral Computed Tomography Perfusion Imaging for the Efficacy of Preoperative Concurrent Chemoradiotherapy in Middle-Aged and Elderly Patients with Locally Advanced Gastric Cancer By: Liang, Jian-Xiao; Bi, XGi-Juan; Li, Xiao-Mei; et al. MEDICAL SCIENCE MONITOR Volume: 24 Pages: 235-245 Published: JAN 122018

(4) Free Published Article From Hepository

Figure 2. Citations of the"Metalloproteinases and their Inhibitors in Patients with Inguinal Hernia"at Web of Science.

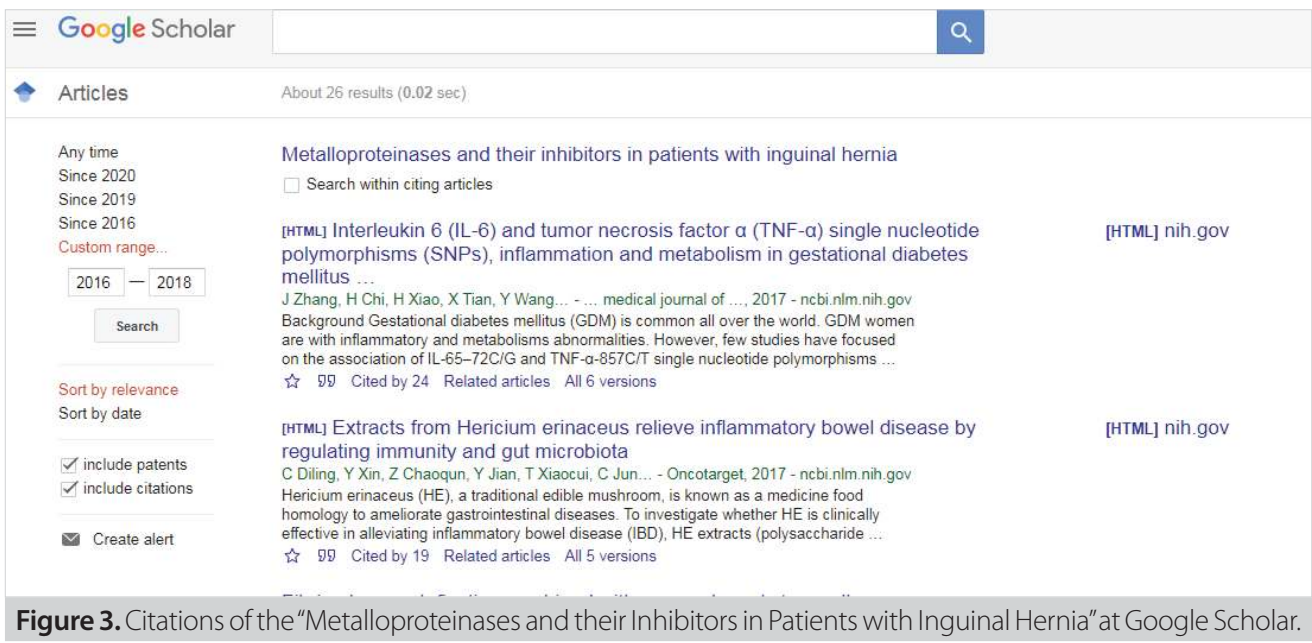

\section{REFERENCES}

1. Kulaçoğlu H, Celasin H. Most cited 100 articles from Turkey on abdominal wall hernias: a bibliometric study. Turk J Surg 2020; 36(2): 180-91. [CrossRef]
2. Isik A, Gursul C, Peker K, Aydın M, Firat D, Yılmaz I. Metalloproteinases and their inhibitors in patients with Inguinal Hernia. World J Surg 2017; 41(5): 1259-66. [CrossRef]

3. Web of Science-Clarivate Analytics. [CrossRef]

4. Google Scholar. [CrossRef] 